\title{
CIDP, Hashimoto's Thyroiditis and Nephropathy: Autoimmune Syndrome Complex?
}

\author{
S Raghavendra, S Sanjay, $R$ Somashekar, R Ashalatha, SK Shankar
}

Can. J. Neurol. Sci. 2009; 36: 382-384

Demyelinating peripheral neuropathy in Hashimoto's thyroiditis is extremely rare, more so is an association of both with membranous nephropathy. We report a 27 -year-old patient with autoimmune lymphocytic thyroiditis with hypothyroidism, chronic inflammatory demyelinating polyneuropathy and nephrotic syndrome.

\section{Case Report}

A 27-year-old female presented with progressive unsteadiness of gait and pins and needles of the soles and finger tips of both hands, for a two month duration. Simultaneously, she also developed lower limb weakness along with distal upper limb weakness. She did not have any symptoms to suggest cranial nerve involvement, bowel or bladder dysfunction or spasticity. No wasting or fasciculation of the muscles was noted either. She had no memory decline, cognitive impairment or seizures.

Examination showed a regular pulse of 72 beats/min and blood pressure of $130 / 80 \mathrm{mmhg}$ in the right upper limb. Diffuse thyromegaly, mild periorbital and pedal edema, and pallor were present. A mild wasting of the small muscles of the hands was noted. She had a lower motor neuron type of symmetric quadriparesis with normal proximal upper limbs, symmetrical weakness of both the flexors and extensors of the wrists (MRC $4 / 5$ power), the knee extensors (4/5), flexors and extensors of the ankles (4/5) and toes (4/5). All deep tendon reflexes were absent. She had a glove and stocking sensory loss affecting all modalities below the knees and at the fingertips in upper limbs. Romberg's test was positive. Other systemic examination was normal.

Investigations showed T3 of $1.06 \mathrm{ng} / \mathrm{ml}(0.8-2 \mathrm{ng} / \mathrm{ml})$, T4 of $5.51 \mu \mathrm{g} / \mathrm{dl}(4.6-12 \mu \mathrm{g} / \mathrm{dl}), \mathrm{TSH}>100 \mathrm{mIU} / \mathrm{ml}(0.27$ to $4.2 \mathrm{mIU} / \mathrm{ml}$ ) and anti-TPO (AMA) > 600IU/ml (normal $<34$ $\mathrm{IU} / \mathrm{ml}$ ). Hemoglobin, total red blood cell (RBC) and white blood cell (WBC) counts, red cell indices, differential counts, and peripheral smear were normal except for a raised ESR of $115 \mathrm{~mm} / \mathrm{hr}$. Biochemistry revealed serum calcium of $8.8 \mathrm{mg} / \mathrm{dl}$ (8.8-10.6mg/dl); inorganic phosphorous $3.8 \mathrm{mg} / \mathrm{dl}$ (2.5$4.5 \mathrm{mg} / \mathrm{dl})$; alkaline phosphatase $65.8 \mathrm{U} / \mathrm{L}$ (30-120U/L); total proteins $7.9 \mathrm{gm} / \mathrm{dl}(6.6-8.3 \mathrm{~g} / \mathrm{dl}) ;$ albumin $2.7 \mathrm{gm} / \mathrm{dl}(3.8-$ $4.4 \mathrm{mg} / \mathrm{dl})$; globulin $5.2 \mathrm{mg} / \mathrm{dl}(2.8-4.3 \mathrm{mg} / \mathrm{dl})$; urea $16 \mathrm{mg} / \mathrm{dl}(17-$ $43 \mathrm{mg} / \mathrm{dl})$, creatinine $0.7 \mathrm{mg} / \mathrm{dl} .(0.6-1.1 \mathrm{mg} / \mathrm{dl})$; total cholesterol $229 \mathrm{mg} / \mathrm{dl}$ (normal<200 mg/dl); LDL cholesterol $156 \mathrm{mg} / \mathrm{dl}(<100$ $\mathrm{mg} / \mathrm{dl})$; HDL cholesterol $42 \mathrm{mg} / \mathrm{d}$ ( $>40 \mathrm{mg} / \mathrm{dl})$; triglycerides $147 \mathrm{mg} / \mathrm{dl}(<150 \mathrm{mg} / \mathrm{dl})$; VLDL cholesterol was $29 \mathrm{mg} / \mathrm{dl}$ (up to $30 \mathrm{mg} / \mathrm{dl})$. Serum Vitamin $B_{12}$ was $539 \mathrm{pg} / \mathrm{ml}$ (130-770 pg/ml). Serum electrophoresis showed hypoalbuminemia alone. Urine examination showed $3+$ proteinuria and 24 hour urine

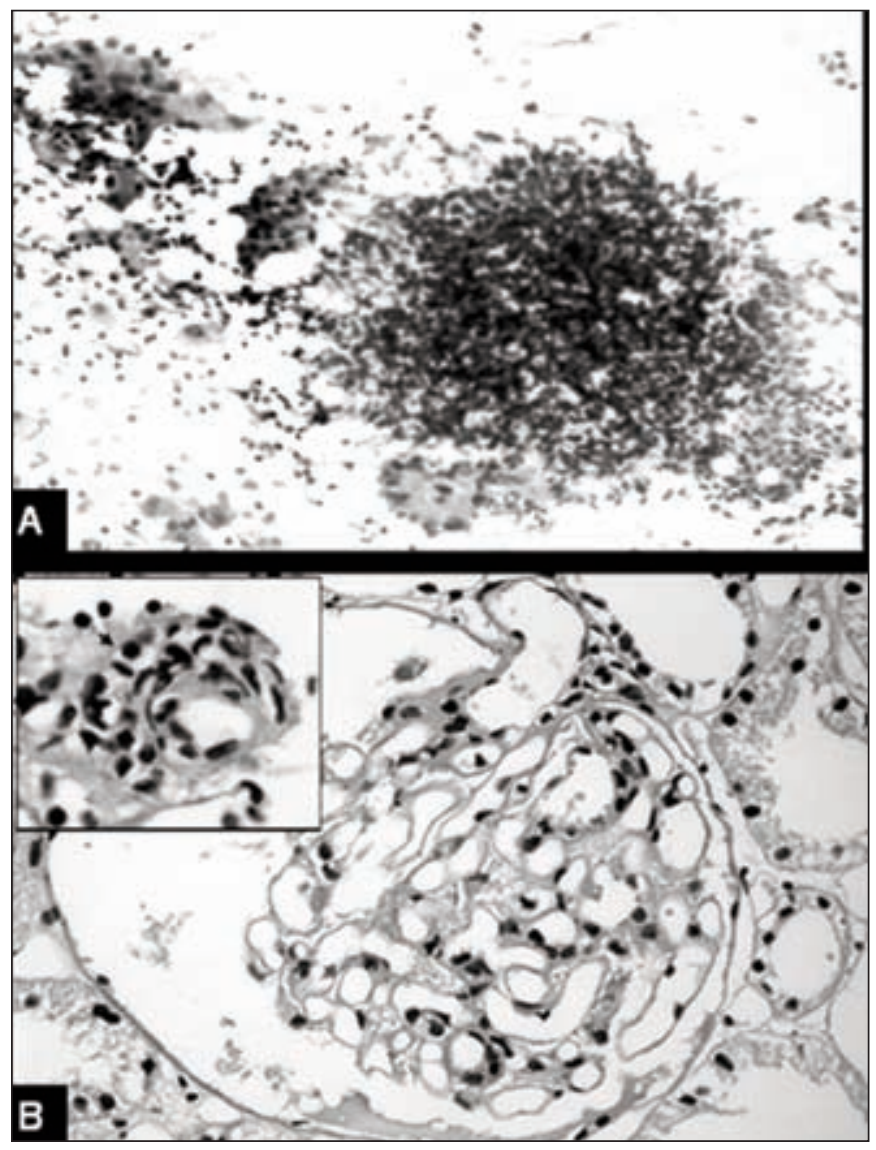

Figure: 1A - Fine needle aspirate from the thyroid shows dense lymphoid aggregate and islands of epithelial cells suggestive of disruption of thyroid acini in a case of Hashimoto's thyroiditis (HE X 160). $1 B$ - Renal glomerulus showing focal mesangial prominence and prominent capillary basement membrane (HE X 200). Insert - a single afferent arteriole which showed perivascular infiltrate of lymphocytes and histiocytes (HE- 320).

From the Department of Neurology (SR), Nephrology (SS), Endocrinology (RS), Kanva Diagnostic Centre; Department of Neuropathology (SKS), National Institute of Mental Health and Neuro Sciences, Bangalore; Department of Neurology (RA), Sree Chitra Tirunal Institute for Medical Sciences and Technology, Trivandrum, India. Received January 14, 2008. Final Revisions Submitted December 11, 2008. Correspondence to: S. Raghavendra, Kanva Diagnostic Centre, Bangalore 560010 India. 
Table: Nerve conduction studies at presentation and four month follow-up

\begin{tabular}{|c|c|c|c|c|c|c|c|c|c|c|}
\hline \multicolumn{11}{|c|}{ Motor nerve conduction studies } \\
\hline \multicolumn{6}{|c|}{ At presentation } & \multicolumn{4}{|l|}{ Four months follow-up } & \\
\hline \multicolumn{2}{|l|}{ Nerve } & \multicolumn{2}{|l|}{ Latency (ms) } & Amplitudes (mv) & $\begin{array}{l}\text { Conduction } \\
\text { velocities }(\mathrm{m} / \mathrm{s})\end{array}$ & Latency (ms) & \multicolumn{2}{|c|}{ Amplitudes (mv) } & $\begin{array}{l}\text { Conduction } \\
(\mathrm{m} / \mathrm{s})\end{array}$ & velocities \\
\hline \multicolumn{2}{|c|}{ Right Median } & \multicolumn{2}{|l|}{9.65} & 2.6 & 30.9 & 6.1 & \multicolumn{2}{|l|}{4.9} & 43 & \\
\hline \multicolumn{2}{|c|}{ Left Median } & \multicolumn{2}{|l|}{7.7} & 4.9 & 36.5 & 5.6 & \multicolumn{2}{|l|}{6.1} & 52 & \\
\hline \multicolumn{2}{|l|}{ Right Ulnar } & \multicolumn{2}{|l|}{8.45} & 4.1 & 40.3 & 4.6 & \multicolumn{2}{|l|}{4.9} & 41 & \\
\hline \multicolumn{2}{|l|}{ Left Ulnar } & \multicolumn{2}{|l|}{5.8} & 5.3 & 41.5 & 3.8 & \multicolumn{2}{|l|}{6.1} & 45 & \\
\hline \multicolumn{2}{|l|}{ Right CPN } & 12.55 & & 2.0 & 22.9 & 10.9 & .3 & & 34 & \\
\hline Left CPN & & 11.30 & & 2.5 & 27.5 & 7.6 & 1.8 & & 37 & \\
\hline Right PTN & & 9.6 & & 9.8 & 32.2 & 9.1 & 0.6 & & 40 & \\
\hline Left PTN & & 10.25 & & 6.4 & 35.1 & 7.9 & 1.4 & & 41 & \\
\hline & & & & & Sensory nerve & duction studies & & & & \\
\hline & At presentation & & & & & & Four months follow- & & & \\
\hline & Nerve & & Peak Laten & $\mathrm{cy}(\mathrm{ms})$ & Amplitudes $(\mu \mathrm{v})$ & $\begin{array}{l}\text { Conduction velocities } \\
(\mathrm{m} / \mathrm{s})\end{array}$ & Peak Latency (ms) & Amp & udes $(\mu \mathrm{v})$ & \\
\hline & Right median & & Unelicitabl & & & & 6.1 & 14 & & \\
\hline & Right ulnar & & Unelicitabl & & & & 5.1 & 19 & & \\
\hline & Left median & & Unelicitabl & & & & 5.8 & 7 & & \\
\hline & Left ulnar & & Unelicitabl & & & & 5 & 11 & & \\
\hline & Right sural & & 3.8 & & 19.96 & 36 & 4.1 & 7 & & \\
\hline & Left sural & & 4.2 & & 20.17 & 32 & 4 & 8 & & \\
\hline
\end{tabular}

F-waves latencies were prolonged from both median and ulnar nerves and absent from the lower limb nerve during the initial test. F-waves reappeared and were prolonged at follow-up. CPN- Common Peroneal Nerve; PTN- Posterior Tibial Nerve

proteinuria was $6214 \mathrm{mgs}$ (normal <160mg/24hours). Microscopy of the urine showed plenty of WBCs and a few granular casts; RBCs $0-2 / \mathrm{HPF}$. There were no bacteria or crystals. Urine Bence Jones protein was negative. Urine Protein/creatine ratio was $3.82(<0.2)$.

Chest $\mathrm{X}$ ray, ECG, and ultrasonographic examination of the abdomen were normal. HIV I and II, HBsAg, HCV antibodies ANA; ANCA (P and C); dsDNA, APLA (IgG and IgM), and serum VDRL were normal. C3 43.3mg/dl (75-135mg/dl) and C4 $2.7 \mathrm{mg} / \mathrm{dl}$ (9-36mg/dl) were low. Antibodies to JO-1; Scl 70; Sm; SS-A; SS-B; Rib.Po; nRNP/Sm; CENP B; histones; nucleosomes; AMA-M2; PM-Scl; Ro-52; and PCNA were all negative.

Fine needle aspiration cytology (FNAC) of both the lobes of thyroid revealed lymphocytic thyroiditis (Figure 1A). A kidney biopsy showed normal glomerular morphology except for a mild increase in mesangial cellularity and matrix in two glomeruli. Perivascular infiltration by lymphocytes was noted in one of the blood vessels adjacent to a glomerulus (Figure 1B). Immunoflorescence studies showed peripheral, mesangial and variable intensity of granular IgG (+++); $\operatorname{IgA}(++)$ and C3 (+) deposits. Silver staining showed thickening of the basement membrane along with subepithelial deposits consistent with membranous nephropathy.

Nerve conduction studies were performed using standard techniques of percutaneous supramaximal stimulation and recording. Nerve conduction revealed sensori-motor demyelinating polyneuropathy with markedly prolonged distal latencies and reduced conduction velocities (Table). CMAPs showed increased dispersion in both the lower limb nerves and upper limbs. There was no conduction block in any of the nerves. Fwaves were all absent in the lower limbs and were prolonged in the upper limb nerves that were tested. Needle EMG was not performed.

Cerebrospinal fluid (CSF) examination showed 1 lymphocyte/cumm; proteins $158.9 \mathrm{mg} / \mathrm{dl}$; glucose $59 \mathrm{mg} / \mathrm{dl}$ (blood glucose $84 \mathrm{mg} / \mathrm{dl} \%$ ); CSF gram and AFB stain, and VDRL were negative. Cerebrospinal fluid anti-TPO (AMA) was $72.7 \mathrm{mg} / \mathrm{dl}$ and CSF-antithyroglobulin was more than $4000 \mathrm{mg} / \mathrm{dl}$. The MRI brain was normal.

She was treated with intravenous methylprednisolone one gram daily for five days followed by oral steroids (prednisolone $60 \mathrm{mg} /$ day). Thyroid hormone supplementation was continued. Her thyroid enlargement almost disappeared within a week. Her 
neuropathy improved gradually. A repeat nerve conduction study at four months showed improvement in both the upper and lower limb nerves though smaller CMAP amplitudes in the lower limb nerves suggested secondary axonal degeneration had occurred between the two studies (Table). She was initiated on ACEinhibitors for nephropathy. As proteinuria continued, mycophenolate was added and titrated to $1500 \mathrm{mg} /$ day. Her renal functions gradually improved. At six month follow-up, she was euthyroid on thyroid hormone supplementation. Clinically, neuropathy was restricted to mildly impaired vibration bilaterally in the feet. Proteinuria was reduced to $940 \mathrm{mg} / 24$ hours. She continued to have elevated antibody titers that were much lower than earlier [AMA 350(normal <34); Anti-TG 2428(normal<115)]. At follow-up, X-ray of the chest, spine and pelvis were normal. At one year, she remained neurologically stable with residual impaired vibration at the toes and renal parameters including 24 urine proteins were normal. She was on $10 \mathrm{mg} /$ day of prednisolone and mycophenolate was being continued.

\section{Discussion}

We hereby report a unique combination of chronic inflammatory demyelinating polyneuropathy (CIDP) with Hashimoto's thyroiditis and membranous nephropathy. Fine needle aspiration of the thyroid revealed lymphocytic thyroiditis with oncocytic changes of the thyroid epithelium. Presence of very high titres of antithyroid antibodies in serum and CSF further supported the diagnosis. The diagnosis of CIDP was established by serial nerve conduction studies and CSF examination. The membranous nephropathy with nephrotic syndrome was reflected by the urinary and biochemical abnormalities and kidney biopsy. There were no manifest features of Hashimoto's encephalopathy unlike the patient with peripheral neuropathy and autoimmune thyroiditis described by Sheng et al. ${ }^{1}$

Peripheral neuropathy as acute and, rarely, as subacute or chronic demyelinating neuropathy in Hashimoto's thyroiditis has been reported..$^{2-10}$ Immunoglobulin responsive motor neuropathy with multifocal conduction blocks with or without elevated GM1 antibodies in patients with Hashimoto's thyroiditis has also been noted. ${ }^{11,12}$ Association of Hashimoto's thyroiditis with immune mediated renal pathology ${ }^{13-17}$, skin lesions ${ }^{7,14,17}$ and encephalopathy ${ }^{18}$ has been recognized earlier. The association of Hashimoto's thyroiditis, CIDP and membranous nephropathy has not been previously reported.

The immunoglobulin deposition in the glomerulus and depletion of the complement in systemic circulation attest to the systemic immune response. The temporal association of the thyroiditis, antithyroid antibodies, demyelinating polyradiculoneuropathy, absence of other antibodies related to vasculitic neuropathies and the clinical and biochemical improvement with immune suppression suggests a causal relationship of immune mediated thyroiditis and neuropathy. The reducing titres of the antibodies correlated with the clinical improvement in our patient. Similar association of the antithyroid antibody titres with clinical course has been observed in Hashimoto's encephalopathy. ${ }^{18}$ The pathophysiology of this autoimmune complex is unclear and complex and various mechanisms including the cell mediated and antibody mediated responses may be operative. ${ }^{19} \mathrm{~A}$ hypothetical mechanism of immune mediated peripheral nerve damage in this setting would perhaps be due to immunoglobulin deposition on the myelinated fibres resulting in conduction block, demyelination or a possible structural homology and epitope sharing of the thyroglobulin peptide fragments with myelin related proteins and a myelinopathy. More studies involving experimental models will be required for proper delineation of this possibility.

\section{REFERENCES}

1. Sheng B, Lau KK, Li HL, Cheng LF. A case of Hashimoto's encephalopathy with demyelinating peripheral neuropathy. Eur Neurol. 2005; 53:84-5.

2. Behar R, Penny R, Powell HC. Guillain-Barré syndrome associated with Hashimoto's thyroiditis. J Neurol. 1986; 233:233-6.

3. Polizzi A, Ruggieri M, Vecchio I, Genovese S, Rampello L, Raffaele R. Autoimmune thyroiditis and acquired demyelinating polyradiculoneuropathy. Clin Neurol Neurosurg. 2001; 103:151-4.

4. Kohli RS, Bleibel W, Bleibel H. Concurrent Immune Thrombocytopenic Purpura and Guillain-Barre Syndrome in a Patient with Hashimoto's Thyroiditis. Am J Hematol. 2007: 82: 307-8.

5. Koblar SA. Hashimoto's thyroiditis associated with acquired idiopathic demyelinating polyradiculoneuropathy. Postgrad Med J. 1991; 67:699-9.

6. Korn-Lubetzki I, Abramsky O. Acute and chronic demyelinating inflammatory polyradiculoneuropathy. Association with autoimmune diseases and lymphocyte response to human neuritogenic protein. Arch Neurol. 1986; 43:604-8.

7. Hart ZH, Hoffman W. Winbaum E. Polyneuropathy, alopecia areata, and chronic lymphocytic thyroiditis. Neurology 1979; 29:106-8

8. Potz G, Neundörfer B. Polyradicular neuritis and Hashimoto's thyroiditis. J Neurol. 1975; 210:283-9.

9. Fritze J, Kountouris D. Hashimoto thyroiditis with polyneuropathy and multiple entrapment syndromes. Nervenarzt. 1984 55:549-51.

10. Awaki E, Onoda K, Takahashi K, Tanaka J. A case of chronic thyroiditis associated with vasculitic neuropathy. Rinsho Shinkeigaku. Clin Neurol. 1988 28:501-6.

11. Toscano A, Rodolico C, Benvenga S, Girlanda P, Laura M, Mazzeo A, et al. Multifocal motor neuropathy and asymptomatic Hashimoto's thyroiditis: first report of an association. Neuromuscul Disord. 2002; 12:566-8.

12. Reisin RC, Zurru C, Buso C, Marchesoni C, Pardal AM, Jadzinsky M. Multifocal motor neuropathy, type 1 diabetes and asymptomatic Hashimoto's thyroiditis: an unusual association. Neuromuscul Disord. 2005; 15:358-60.

13. Shuper A, Leathem T, Pertzelan A, Eisenstein B, Mimouni M. Familial Hashimoto's thyroiditis with kidney impairment. Arch Dis Child. 1987; 62:811-4.

14. Akikusa B, Kondo Y, Iemoto Y, Iesato K, Wakashin M. Hashimoto's thyroiditis and membranous nephropathy developed in progressive systemic sclerosis (PSS). Am J Clin Pathol. 1984; 81:260-3.

15. Sasaki H, Joh K, Ohtsuka I, Ohta H, Ohhashi T, Hoashi S, et al. Interstitial nephritis associated with glomerulonephritis in a patient with Hashimoto's disease and idiopathic portal hypertension. Intern Med. 1992; 31:641-8.

16. Nishiki M, Murakami Y, Yamane Y, Kato Y. Steroid-sensitive nephrotic syndrome, sarcoidosis and thyroiditis-a new syndrome? Nephrol Dial Transplant 1999; 14:2008-10.

17. Kuzmanovska DB, Shahpazova EM, Kocova MJ, Gruevska SJ, Petrushevska G. Autoimmune thyroiditis and vitiligo in a child with minimal change nephrotic syndrome. Pediatr Nephrol. $2001 ; 16: 1137-8$

18. Canton A, de Fabregas O, Tintore M, Mesa J, Codina A, Simo R: Encephalopathy associated to autoimmune thyroid disease: A more appropriate term for an underestimated condition? J Neurol Sci. 2000; 176:65-9

19. Said G. Chronic inflammatory demyelinating polyneuropathy. Neuromuscul Disord. 2006; 16:293-303. 